\title{
HUBUNGAN ANTARA SUASANA (CLIMATE) BELAJAR DENGAN SIKAP PENOLAKAN BOLOS SEKOLAH DARI SISWA SMP NEGERI 15 MEDAN
}

\author{
R. L. Holmes Parhusip \\ Surel: holmesphsp720@gmail.com
}

\begin{abstract}
This study aims to examine the truth of the relationship between the atmosphere of learning and the attitude of refusal to skip student school. This research was conducted at the 15 Medan State Middle School in the academic year 2017/2018. The population in this study were all second grade students of Medan State Middle School totaling 360 people. The sampling technique used in this study is random sampling. The sample of this study is 90 people, namely 25\% of the population. From the results of the analysis carried out conclusions the level of tendency of the Learning Atmosphere in SMP Negeri 15 Medan is still lacking and sufficient. The tendency for the attitude of rejecting school absenteeism from second grade students of SMP Negeri 15 Medan is quite high. There is a relationship that is positively and significantly directly proportional between the learning atmosphere and the attitude of refusal to skipping school actions from the second grade students of SMP Negeri 15 Medan.
\end{abstract}

Keywords: Climate, Relationships, Learning, Cakes Attitude

\begin{abstract}
ABSTRAK
Penelitian ini bertujuan untuk menguji kebenaran hubungan suasana belajar dengan sikap penolakan untuk bolos sekolah siswa. Penelitian ini dilakukan di SMP Negeri 15 Medan tahun pelajaran 2017/2018. Populasi dalam penelitian ini adalah semua siswa kelas dua SMP Negeri 15 Medan berjumlah 360 orang. Teknik sampling yang dipergunakan dalam penelitian ini adalah random sampling. Sample penelitian ini adalah sebanyak 90 orang, yaitu 25\% dari populasi. Dari hasil analisis yang dilakukan ditarik kesimpulan tingkat kecenderungan Suasana Pembelajaran di SMP Negeri 15 Medan masih kurang dan cukup.Tingkat kecenderung sikap penolakan bolos sekolah dari siswa kelas dua SMP Negeri 15 Medan adalah cukup tinggi. Ada hubungan berbanding lurus yang positif dan signifikan antara suasana pembelajaran dengan sikap penolakan terhadap tindakan bolos sekolah dari siswa kelas dua SMP Negeri 15 Medan.
\end{abstract}

Kata Kunci: Climate, Hubungan, Belajar, Sikap Bolos

\section{PENDAHULUAN}

Pembelajaran adalah proses interaksi peserta didik dengan pendidik dan sumber belajar pada suatu lingkungan belajar.

Sasaran pembelajaran itu adalah subjek didik agar memiliki pengetahuan serta keterampilan yang memadai sehingga dapat dipergunakan untuk menyelesaikan masalah yang dihadapinya dan yang dihadapi oleh masyarakatnya. Seseorang yang mampu menyelesaikan masalah pribadi 
dan masyarakatnya adalah manusia yang telah dewasa. Kedewasaan seseorang dipengaruhi tingkat kualitas ilmu pengetahuan dan keterampilan yang dimiliki seseorang. Tingkat kualitas pengetahuan dan keterampilan yang tinggi akan tercapai jika proses pembelajaran yang direncanakan dan dilaksanakan adalah baik, serta sarana dan prasarana pendikan itu tercukupi dengan tingkat kualitas yang baik pula. Tingkat kualitas pendidikan nasional selalu dianggap masih rendah, sehingga kemampuan menyelesaikan masalah yang dimiliki oleh siswa sangat rendah. Rendahnya kualitas pendidikan nasionaal disebabkan oleh rendahnya kualitas institusi yang ada serta kebijakan pendidikan selama ini terkesan hanya cobacoba tanpa pertimabagan yang matang, dam hal ini sesungguhnya memperlihatkan kualitas yang rendah dari penentu kebijakan itu sendiri. Rendahnya anggaran Negara untuk sektor pendidikan berdampak besar terhadap rendahnya kualitas pendidikan nasional. Sarana dan prasaran belajar yang minim, tingkat kesejahteraan pendidik yang sangat minim, tingkat kesejahteraan pendidik yang sangat rendah, metode pembelajaran yang tidak bervariasi dan terkesan membosankan.

Sukaryono (2004) melihat permasalahan kualitas siswa lulusan sekolah disebabkan factor guru. Dikatakan bahwa banyak guru yang mempunyai kepribadian otoriter dengan gaya mengajar otoriter, sehingga siswa tidak diberi kesempatan bernalar secara objektif dan kreatif. Guru akan menampakkan sikap kasar sehingga mengakibatkan siswa merasam takut kepada guru tersebut. Ketakutan siswa akan menyebabkan terbenamnya dan tidak berkembangnya potensi diri siswa. Dengan demikian seharusnya guru memiliki sikap ramah dan lemah lembut dalam melaksanakan tugas kependidikan. Sikap ramah dan lemah lembut guru akan memancing keberanian dan keterbukaan siswa kepada guru sehingga terjadi system pembelajaran dan komunikasi yang terbuka dan kondusif. Sikap ramah dan lemah lembut sesungguhnya akan membuat suasana (Climate) pembelajaran dan kondusif.

Suasana pembelajaran yang kondusif adalah suatu kondisi dan situasi lingkungan belajar yang menyenangkan bagi siswa dan guru, sehingga siswa mampu tetap tinggal di suatu tempat dalam waktu yang cukup lama untuk melakukan kegiatan belajar. Suasana pembelajaran yang kondusif akan muncul jika proses pembelajaran yang terjadi bersifat demokratis dan guru tidak bersifat otoriter. Akan tetapi suasana belajar yang kondusif sering sekali hal yang terlupakan dan tidak disadari oleh guru maupun pihak pengelola sekolah (Jamilah, 2005). 
R. L. Holmes Parhusip : Hubungan Suasana (Climate) ...

Banyak siswa yang bolos sekolah dikarenakan suasana belajar yang tidak menarik bahkan membuat siswa itu sendiri stress. Akan tetapi hal ini perlu dipertanyakan kebenarannya. Sejalan dengan hal itu penelitian ini bertujuan untuk menguji kebenaran hubungan suasana belajar dengan sikap penolakan untuk bolos sekolah siswa.

Adapun tujuan penelitian ini adalah untuk melihat Tingkat hubungan antara suasana pembelajaran dengan sikap penolakan tindakan bolos siswa kelas dua SMP Negeri 15 Medan tahun pelajaran 2017/2018.

\section{METODE PENELITIAN}

Penelitian ini dilakukan di SMP Negeri 15 Medan tahun pelajaran 2017/2018. Populasi dalam penelitian ini adalah semua siswa kelas dua SMP Negeri 15 Medan berjumlah 360 orang. Teknik sampling yang dipergunakan dalam penelitian ini adalah random sampling. Sample penelitian ini adalah sebanyak 90 orang, yaitu $25 \%$ dari populasi.

Adapun desain penelitian ini adalah penelitian korelasional, seperti yang diperlihatkan berikut ini:

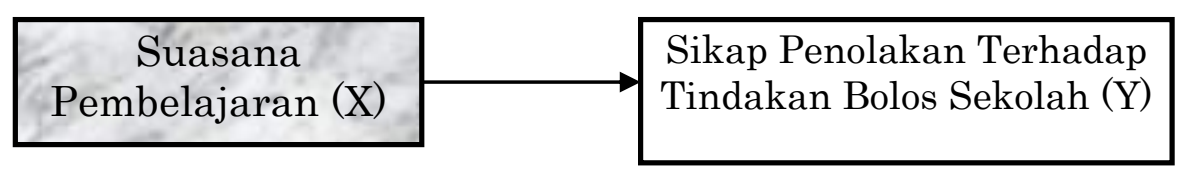

Teknik Analisis Data

Analisis deskriptif yang

dilakukan adalah dengan menggunakan skor ideal seperti table 1 dibawah ini.

Tabel 1. Pedoman Hasil Analisis

\begin{tabular}{c|l|c}
\hline Kelas & \multicolumn{1}{|c}{ Rentangan Skor } & Kriteria Penguasaan \\
\hline \hline 1 & $\mathrm{Mi}+1,5 \mathrm{Sdi} / \mathrm{d}$ atas & Tinggi \\
2 & $\mathrm{Mi} \mathrm{s} / \mathrm{di}+1,5 \mathrm{SDi}$ & Cukup Tinggi \\
3 & $\mathrm{Mi}-1,5 \mathrm{SDi}$ s/d Mi & Kurang \\
4 & Bawah $/ \mathrm{d} \mathrm{Mi}-1,5 \mathrm{SDi}$ & Rendah \\
\hline
\end{tabular}

Dimana :

SDi $=$ Standard deviasi ideal

(Skor ideal maksimum - skor ideal minimum)/6

$\mathrm{Mi}=$ Rata - rata ideal

(Skor ideal maksimum - skor ideal minimum)/2

Untuk menjawab masalah ketiga, dimana dirumuskan dalam bentuk hipotesis dan diuji dengan statistik inferensial. 
Hipotesis yang diuji adalah hipotesis alternative (Ha) yang merupakan tandingan dari hipoteis nol (Ho). Hipotesis diuji dengan uji korelasi product moment.

- Terima Hipotesis Alternatif (Ha), jika $\mathrm{r}$ hitung > $\mathrm{r}$ table dengan taraf signifikansi $95 \%$, maka Ha terima maka hal ini sekaligus menolak hipotesis nol (Ho), yang merupakan tandingan dari Ha.

- Tolak Hipotesis Alternatif (Ha), jika $\mathrm{r}$ hitung $<\mathrm{r}$ table dengan taraf signifikansi $95 \%$.

Uji normalitas dengan menggunakan metode normalitas Chi kuadrat.

Uji linieritas menggunakan rumus :

$$
F o=\frac{S^{2} T C}{S^{2} G} ;
$$

Dengan derajat kebebasan, Tuna Cocok/Galat $=(\mathrm{k}-2) / \mathrm{n}-\mathrm{k})$

Jika Fo<Ft dengan taraf signifikansi 95\%, maka bentuk regresi adalah linier.

$$
\text { Uji keberartian }
$$

menggunakan rumus :

$$
F o=\frac{S^{2} r e g}{S^{2} S i s} ;
$$

Dengan derajat kebebasan (n-2). Jika Fo >Ft, dengan taraf signifikansi $95 \%$ maka arah koefisien regresi adalah berarti.

Uji normalitas sebaran data dapat dianalisis dengan rumus Chi kuadrat berikut $\mathrm{Fo}=\mathrm{DD} / \mathrm{Fh}$; dengan perhitungan seperti langkah berikut, dalam hal ini diperlihatkan dalam bentuk pengisian tabel berikut ini:

Tabel 2. Tabel Pengujian Normalitas Sebaran Data

\begin{tabular}{c|l|l|l|l|l|l}
\hline Kelas & \multicolumn{1}{|c|}{ Interval } & Fo & Fh & D & DD & DD/Fh \\
\hline \hline 1 & M + 2SD s/d atas & & & & & \\
2 & M + 1SD s/d M + 2 SD & & & & & \\
3 & M s/d M + 2 SD & & & & & \\
4 & M - 1SD s/d M & & & & & \\
5 & M - 2SD s/d M - 1SD & & & & & \\
6 & Bawah s/d M - 2SD & & & & & \\
\hline \hline & Jumlah & & & & & \\
\hline
\end{tabular}

Dimana

Fo = Frekuensi observasi

$\mathrm{Fh}=$ Frekuensi harapan

$\mathrm{D}=\mathrm{Fo}-\mathrm{Fh}$

$\mathrm{DD}=(\mathrm{Fo}-\mathrm{Fh})^{2}$

- Derajat kebebasan uji normalitas adalah jumlah kelas $-1=6-1=5$
- Jika Fo < Ft, dengan taraf signifikansi 95\%, maka sebaran data adalah normal 
R. L. Holmes Parhusip : Hubungan Suasana (Climate) ...

HASIL PENELITIAN DAN PEMBAHASAN
A. Distribusi
Subjek
Penelitian Menurut Sikap
Penolakan Tindakan
Bolos (Y)

Tabel 3. Distribusi Subjek Penelitian Menurut Sikap Penolakan Tindakan $\operatorname{Bolos}(\mathbf{Y}), \mathbf{N}=90$

\begin{tabular}{c|c|c|c}
\hline No. & Interval Kelas & $\begin{array}{c}\text { Frekuensi Absolut } \\
\text { (Frekuensi Observasi) }\end{array}$ & Frekuensi Relatif \\
\hline 1 & $78.41-$ atas & 0 & 0.00 \\
2 & $67.16-78.40$ & 12 & 13.32 \\
3 & $55.91-67.15$ & 34 & 37.74 \\
4 & $44.66-55.90$ & 25 & 27.75 \\
5 & $33.41-44.65$ & 19 & 21.09 \\
6 & Bawah -33.40 & 0 & 0.00 \\
\hline \hline
\end{tabular}

Sumber : Olahan penulis, Oktober 2006

Dilihat dari tabel 3 tersebut di atas, dapat diketahui bahwa sebaran data subjek penelitian terbanyak menurut sikap penolakan tindakan bolos (Y) adalah pada interval kelas 44.66 s/d 55.90 dan pada interval 55.91 s/d 67.15, yaitu masing -masing 25 dan 34 orang.

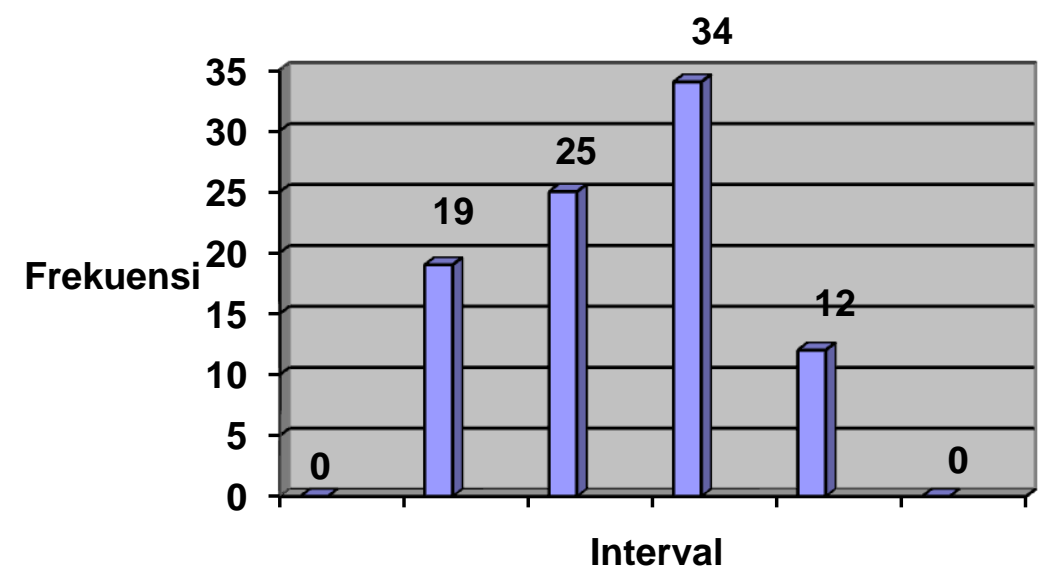

Gambar 1. Grafik Sebaran Data Subjek Penelitian Menurut Sikap Penolakan Tindakan Bolos (Y) 

B. Distribusi Subjek Penelitian Menurut Suasana Pembelajaran
Mean (rata-rata) dan Standard Deviasi ubahan $\mathrm{X}$, masing-masing adalah sebesar 37.18 dan 14.62 .

Tabel 4. Distribusi Subjek Penelitian Menurut Suasana Pembelajaran Bolos (Y), $\mathbf{N}=\mathbf{9 0}$

\begin{tabular}{c|c|c|c}
\hline No. & Interval Kelas & $\begin{array}{c}\text { Frekuensi Absolut } \\
\text { (Frekuensi Observasi) }\end{array}$ & Frekuensi Relatif \\
\hline \hline 1 & $96.44-$ atas & 0 & 0.00 \\
2 & $81.81-96.43$ & 16 & 17.76 \\
3 & $67.18-81.80$ & 26 & 28.86 \\
4 & $52.55-67.17$ & 36 & 39.96 \\
5 & $37.92-52.54$ & 9 & 9.99 \\
6 & Bawah -37.91 & 3 & 3.33 \\
\hline \hline
\end{tabular}

Sumber : Olahan penulis, Oktober 2006

Pada gambar 2. dibawah ini memperlihatkan grafik sebaran

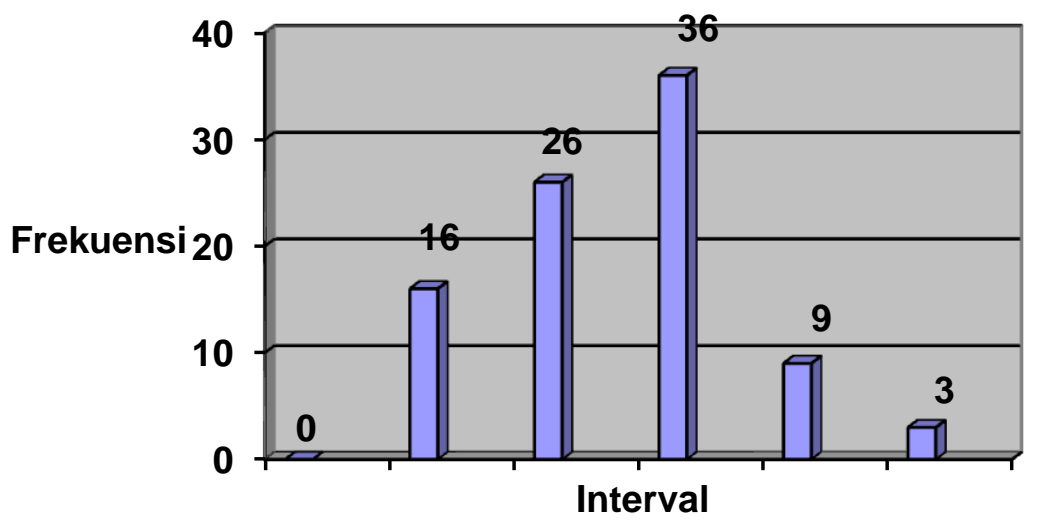

Gambar 2. Grafik Sebaran Data Subjek Penelitian Menurut Susana

C. Tingkat Kecenderungan Sikap Penolakan Bolos (Y)

Sikap penolakan bolos mempunyai mean (rata rata) ideal dan standar deviasi ideal data subjek penelitian menurut suasana pembelajara (Y).

\section{Pembelajaran (X)}


R. L. Holmes Parhusip : Hubungan Suasana (Climate) ...

Tabel 5. Distribusi Subjek Penelitian Menurut Susana Pembelajaran (Y)

$$
\mathbf{N}=90
$$

\begin{tabular}{c|c|c|c}
\hline No. & Interval Kelas & Frekuensi Observasi & Kriteria \\
\hline 1 & $66.68-$ atas & 28 & Tinggi \\
2 & $55.00-66.67$ & 43 & Cukup \\
3 & $43.32-54.99$ & 19 & Kurang \\
4 & Bwah -43.31 & 0 & Rendah \\
\hline \hline
\end{tabular}

Dari tabel di atas, dapat diketahui bahwa kecenderungan sikap penolakan bolos dari siswa kelas dua SMP Negeri 15 Medan adalah cukup tinggi, yaitu masingmasing sebanyak 43 dan 28 orang. Untuk lebih jelasnya ditunjukkan pada grafik berikut ini.

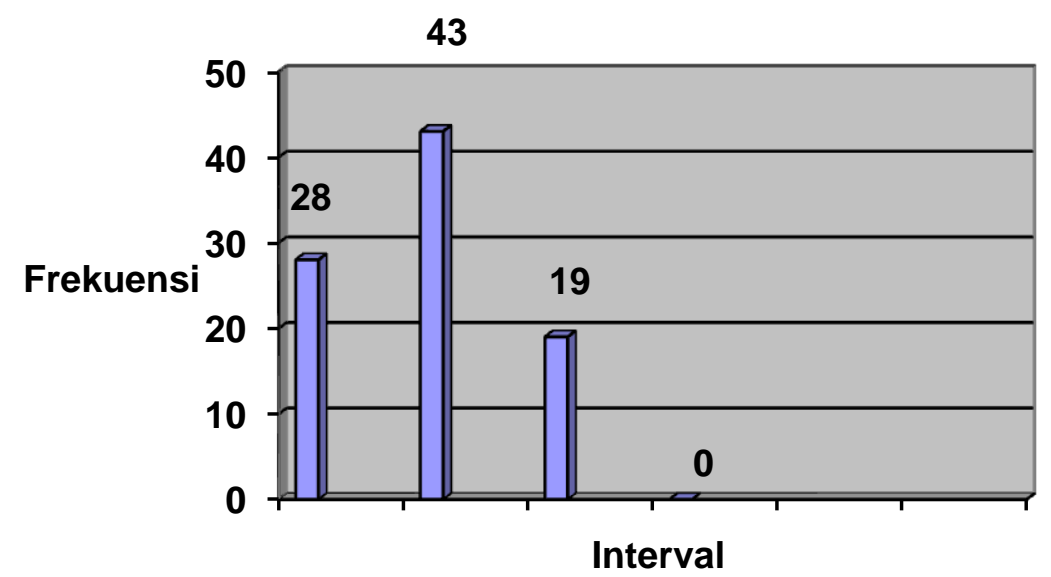

Gambar 3. Grafik Tingkat Kecenderungan Sikap Penolakan Bolos

Tabel 6. Tingkat Kecenderungan Suasana Pembelajaran $(X), \mathbf{N}=90$

\begin{tabular}{c|c|c|c}
\hline No. & Interval Kelas & Frekuensi Observasi & Kriteria \\
\hline \hline 1 & $76.67-$ atas & 0 & Tinggi \\
2 & $60.00-76.66$ & 43 & Cukup \\
3 & $43.33-59.99$ & 27 & Kurang \\
4 & Bawah -43.32 & 0 & Rendah \\
\hline \hline
\end{tabular}

Pada table 6 di atas, dapat diketahui bahwa kecenderungan Susana pembelajaran di SMP
Negeri 15 Medan adalah kurang, yaitu 27 orang da, cukup 43 orang. 
Tabel 7. Rangkuman Hasil Uji Linieritas Hubungan Ubahan Susana Pembelajaran (SP) dengan Sikap Penolakan Bolos (SPB)

\begin{tabular}{c|c|c|c|c|c|c|c}
\hline No. & $\begin{array}{c}\text { Jenis } \\
\text { Ubahan }\end{array}$ & SV & db & JK & KR & \multicolumn{2}{|c}{ Harga F } \\
\hline \hline 1 & SP & TC & 22 & 15388 & 70.98 & Fh $=$ & Ft $=1.95$ \\
& SPB & G & 31 & 1265 & 26.32 & 2.69 & \\
\hline
\end{tabular}

Sumber : Olahan penulis, Oktober 2006

Dengan mengkonsultasikan Fh terhadap $\mathrm{Ft}$ dengan taraf signifikansi $95 \%$ dan dengan $\mathrm{db}=$
22/31, maka Fh>Ft, dengan demikian bentuk regresi adalah linier.

\section{Grafik Hubungan X dengan Y}

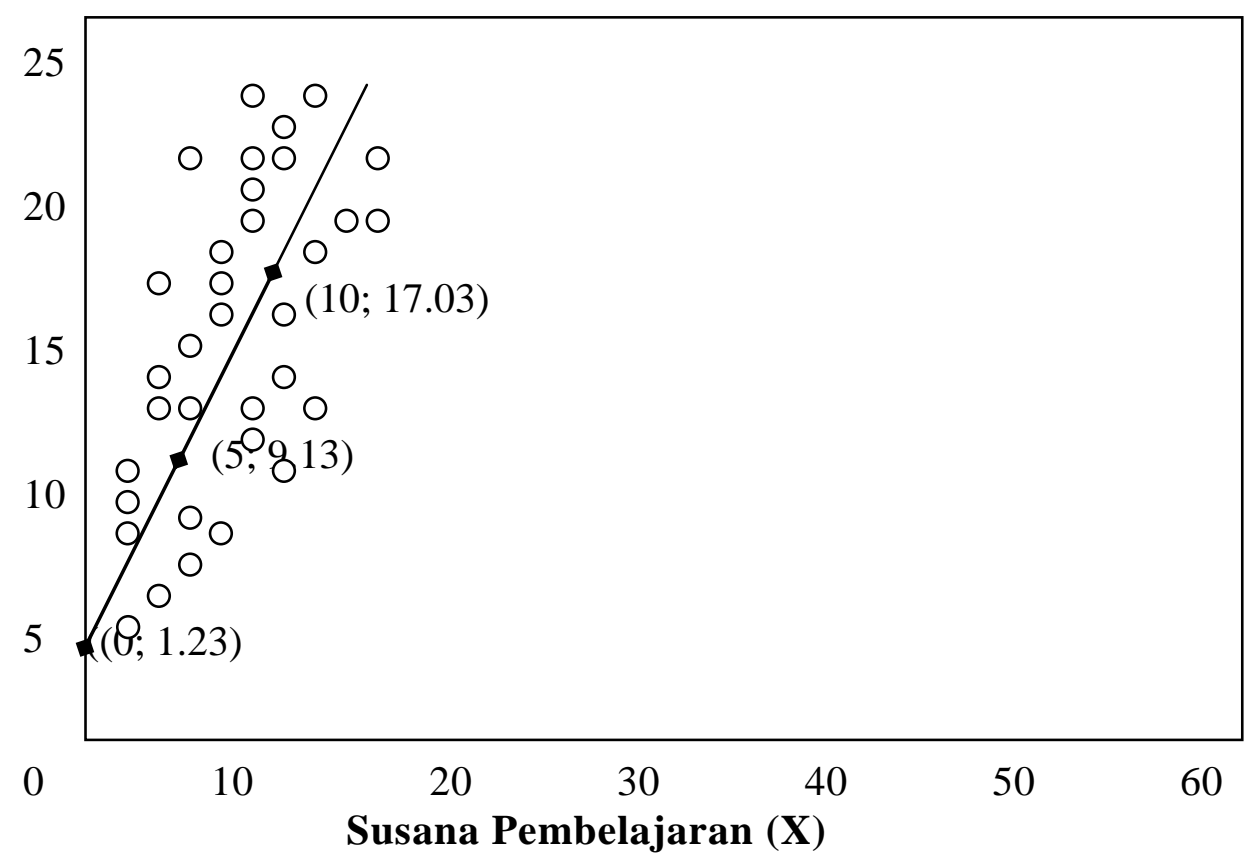

Gambar 4. Grafik Sebaran Data Hubungan Susana Pembelajaran dengan Sikap Penolakan Bolos

Uji Keberartian Bentuk Regresi

Uji keberatian dihitung dengan Fo $=\mathrm{S}_{2} \mathrm{reg} / \mathrm{S}_{2} \mathrm{Sis}=$ 986,2176/59.380 =16.6 dengan mengkonsultasikan Fo dengan Ftabel $95 \%$ dengan $\mathrm{db}=1 / 89=$ 7.47; maka harga Fo $>\mathrm{Ft}=$ 16.61>7.47, maka dengan demikian koefisien arah garis regresi adalah berarti.

\section{Uji Normalitas}

Uji normalitas sikap penolakan bolos (y) dapat dilihat pada table 8, dan uji normalitas ubahan Susana Pembelajaran (X) dapat dilihat pada table 8 dan table 9 berikut ini. 
R. L. Holmes Parhusip : Hubungan Suasana (Climate) ...

Tabel 8. Uji Normalitas Ubahan Sikap Penolakan Bolos (Y)

\begin{tabular}{c|c|c|c|c|c|c}
\hline No. & Interval & Fo & Fh & D & DD & DD/FH \\
\hline \hline 1 & $78.41-$ atas & 0 & 1.80 & 1.80 & 3.24 & 1.80 \\
2 & $67.16-78.40$ & 12 & 12.60 & 0.60 & 0.36 & 0.03 \\
3 & $55.91-67.15$ & 25 & 30.60 & 5.60 & 31.36 & 1.02 \\
4 & $44.66-55.90$ & 34 & 30.60 & 0.60 & 0.36 & 0.0 \\
5 & $33.41-55.90$ & 19 & 12.60 & 0.40 & 40.96 & 3.25 \\
6 & Bawah - 33.40 & 0 & 1.80 & 1.80 & 3.24 & 1.80 \\
\hline \hline \\
db $=\mathbf{5}$ dan $\mathbf{F t}_{\mathbf{0 . 0 5}}=\mathbf{1 1 , 0 7}$
\end{tabular}

Grafik Hubungan X dengan $Y$

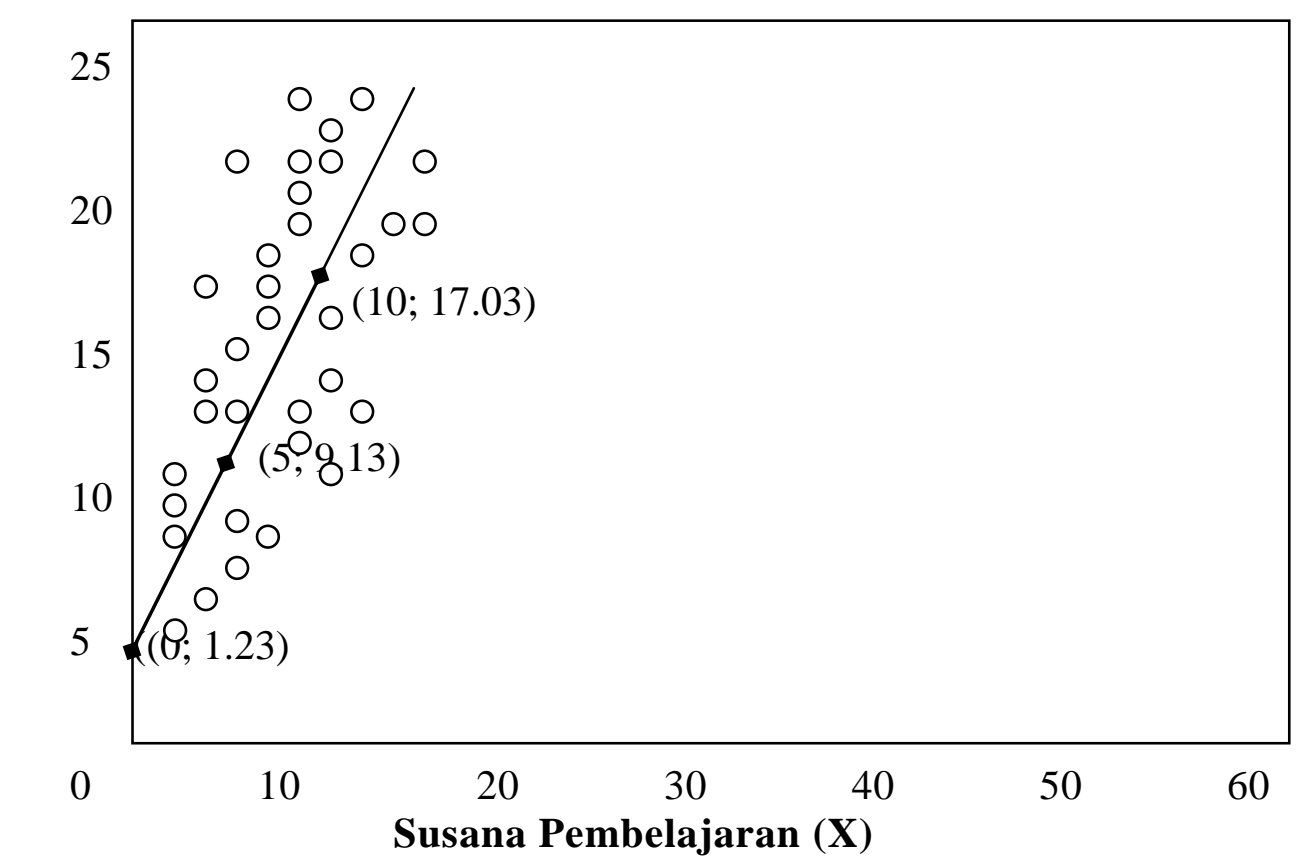

Gambar 4. Grafik Sebaran Data Hubungan Susana Pembelajaran dengan Sikap Penolakan Bolos

\section{Uji Keberartian Bentuk Regresi}

Uji keberatian dihitung dengan Fo $=\mathrm{S}_{2} \mathrm{reg} / \mathrm{S}_{2} \mathrm{Sis}=$ 986,2176/59.380 =16.6 dengan mengkonsultasikan Fo dengan Ftabel $95 \%$ dengan $\mathrm{db}=1 / 89=$ 7.47; maka harga $\mathrm{Fo}>\mathrm{Ft}=$ 16.61>7.47, maka dengan demikian koefisien arah garis regresi adalah berarti.

\section{Uji Normalitas}

Uji normalitas sikap penolakan bolos (y) dapat dilihat pada table 8, dan uji normalitas ubahan Susana Pembelajaran (X) dapat dilihat pada table 8 dan table 9 berikut ini. 
Tabel 8. Uji Normalitas Ubahan Sikap Penolakan Bolos (Y)

\begin{tabular}{c|c|c|c|c|c|c}
\hline No. & Interval & Fo & Fh & D & DD & DD/FH \\
\hline \hline 1 & $78.41-$ atas & 0 & 1.80 & 1.80 & 3.24 & 1.80 \\
2 & $67.16-78.40$ & 12 & 12.60 & 0.60 & 0.36 & 0.03 \\
3 & $55.91-67.15$ & 25 & 30.60 & 5.60 & 31.36 & 1.02 \\
4 & $44.66-55.90$ & 34 & 30.60 & 0.60 & 0.36 & 0.0 \\
5 & $33.41-55.90$ & 19 & 12.60 & 0.40 & 40.96 & 3.25 \\
6 & Bawah-33.40 & 0 & 1.80 & 1.80 & 3.24 & 1.80 \\
\hline \hline
\end{tabular}

$\mathrm{db}=5$ dan $\mathrm{Ft}_{0.05}=11,07$

Dengan demikian Fo $<\mathrm{Ft}$ $7,91<11,07$, maka sebaran data

sikap penolakan bolos (Y) adalah normal.

Tabel 9. Uji Normalitas Ubahan Susana Pembelajar (X)

\begin{tabular}{c|c|c|c|c|c|c}
\hline No. & Interval & Fo & Fh & D & DD & DD/FH \\
\hline \hline 1 & $96.44-$ atas & 0 & 1.80 & 1.80 & 3.24 & 1.80 \\
2 & $81.81-96.43$ & 16 & 12.60 & 3.40 & 3.40 & 0.92 \\
3 & $67.18-81.80$ & 26 & 30.60 & 4.60 & 4.60 & 0.69 \\
4 & $52.55-67.17$ & 36 & 30.60 & 5.40 & 5.40 & 0.95 \\
5 & $37.92-52.54$ & 9 & 12.60 & 3.60 & 3.60 & 1.03 \\
6 & Bawah - 37.91 & 3 & 1.80 & 1.20 & 1.20 & 0.80 \\
\hline \hline
\end{tabular}

$\mathrm{db}=5$ dan $\mathrm{Ft}_{0.05}=11,07$

Dengan demikian Fo $<\mathrm{Ft}$ $6.19<11,07$, maka sebaran data sikap penolakan bolos (Y) adalah normal.

\section{Pengujian Hipotesis}

Hasil perhitungan keofisien korelasi $r_{x y}=0.52$. dengan mengkonsultasikannya dengan $r$ table dengan tarf signifikansi $95 \%$ dengan jumlah subjek penelitian 90 orang, yaitu diperoleh 0,207, maka $r_{x y}>r_{t}$, yaitu $0.52>0.245$, maka dengan demikian hipoteisis Nol (Ho) yang diuji adalah ditolak. Penolakan hipotesis nol adalah penerimaan hipoteisis alternative
(Ha). Bunyi kedua hipotesis tersebut adalah sebagai berikut :

$\mathrm{Ha}:$ Ada hubungan berbanding lurus yang positif dan signifikan antara suasan pembelajaran dengan sikap penolakan terhadap tindakan bolos sekolah dari siswa kelas dua SMP Negeri 15 Medan

Ho : Tidak ada hubungan berbanding lurus yang positif dan signifikan antara suasan pembelajaran dengan sikap penolakan terhadap 
R. L. Holmes Parhusip : Hubungan Suasana (Climate) ...

tindakan bolos sekolah dari siswa kelas dua SMP Negeri 15 Medan

\section{SIMPULAN}

Berdasarkan hasil penelitian dan implikasi yang telah diuraikan di atas, maka rumuskan kesimpulan sebagai berikut:

a. Tingkat kecenderungan Suasana Pembelajaran di SMP Negeri 15 Medan masih kurang dan cukup.

b. Tingkat kecenderung sikap penolakan bolos sekolah dari siswa kelas dua SMP Negeri 15 Medan adalah cukup tinggi.

c. Ada hubungan berbanding lurus yang positif dan signifikan antara suasan pembelajaran dengan sikap penolakan terhadap tindakan bolos sekolah dari siswa kelas dua SMP Negeri 15 Medan

\section{DAFTAR PUSTAKA}

Arikunto, S. 2003. Dasar-Dasar Evaluasi Pendidikan. Jakarta: Bina Aksara

Ancok, Djamaludin. 1986. Teknik Penyusunan Skala Pengukur. Yogyakarta: Pusat Penelitian Kependudukan UGM Yogyakarta.

Fadjar, Malik. 2003. UndangUndang Republik Indoneisia Nomor 20 Tahun 2003 Tentang Sistem Pendidikan Nasional. Jakarta: Depdiknas.
Fernandes, H. J. X. 1980. Item Analisis. Jakarta: Litbang Dikbud.

Jamilah. 2005. Merancang Pendidikan Yang Demokratis. Gerbang Majalah Pendidikan, Edisi 11 Th IV.

Joy, Galon Sylor, att, All. 1978. Curriculum Planning For Better Teaching and Learning. New York: Holt Renihard and Winston.

Kerlinger, N. Fred, Elazar J. Penhadjur. 1973. Multiple Regression Behacioral Resarch. New York: Holt Rinehart and Winston, Inc.

Natawidjaya, Rochman. 1985. Psikologi Perkembangan Manusia. Jakarta: Rajawali.

Pujiyono, JO. 2004. Memimpikan Pendidikan yang Menjamin Kesejahteraan. Jakarta: Gerbang Majalah Pendidikan, Edisi 4 Th. IV.

Purwanto, M. Ngalim. 1994. Psikologi Pendidikan. Bandung: Remaja Karya.

Suryadi, Ace. 2003. Tantangan Pendidikan di Era Desentralisasi, Buletin Pusat Perbukuan. Jakarta: Depdiknas, Vol 9.

Sukaryono. 2004. Demkoratisasi Guru Mepercepat Peningkatan Mutu Pendidikan. Jakarta: Gerbang Majalan pendidikan, Edisi 2 Th. IV.

Sihombing, LM., W. Pangaribuan., Abdul Muin Sibuea, Salim, 
BJ. Lumbantoruan. 1991.

Studi Tantangan Suasana (Climate) di IKIP Medan (kajian Kasus FPTK - IKIP Medan). Laporan Penelitian. Medan: FPTK IKIP Medan.

Silver, Paula. 1986. Educational Administration. New York: Harper \& Row Publisher. Inc.

Walgito, Bimo. 1981. Bimbingan dan Penyuluhan di Sekolah. Yogyakarta: Fakultas Psikologi UGM Yogyakarta. 